\title{
Chloroquine treatment in desquamative interstitial pneumonia
}

\author{
C SPRINGER, C MAAYAN, Z KATZIR, I ARIEL, AND S GODFREY \\ Departments of Pediatrics and Pathology, Hadassah University Hospital, Jerusalem, Israel
}

SUMmaRY An infant presented with failure to thrive, tachypnoea, and hypoxia reversed by oxygen. Lung function showed decreased pulmonary compliance; lung biopsy showed desquamative interstitial pneumonitis. Chloroquine $10 \mathrm{mg} / \mathrm{kg} /$ day resulted in improvement and relapse when temporarily stopped. The patient was completely asymptomatic during four years' treatment and six months after stopping treatment.

Desquamative interstitial pneumonia is uncommon in infancy, and although the histological features resemble those of adults, the clinical presentation and response to treatment tend to differ. Infants have a rapidly progressive disease characterised by tachypnoea, dyspnoea, cough, cyanosis reversed by oxygen, and hyperinflation of the lungs. ${ }^{1}$ Although spontaneous remissions have been reported, ${ }^{2}$ it is usually a fatal disease unless treated. The usually accepted treatment is with corticosteroids or a combination of corticosteroids and cytotoxic drugs. Even when treated, the mortality in infancy can be up to $50-60 \%$.

An alternative approach to treatment was reported by Tooley, who obtained a good response to treatment with chloroquine in a girl with desquamative interstitial pneumonia. ${ }^{3}$

We present a report of an infant with severe desquamative interstitial pneumonia in which we obtained objective evidence of a dramatic response to chloroquine.

\section{Case report}

A 4 month old boy was admitted because of anorexia and poor weight gain from the age of 2 months. He was born after a normal pregnancy, weighing $3150 \mathrm{~g}$, and the history was otherwise unremarkable. An older sibling had been admitted with a similar problem of failure to thrive, which was eventually diagnosed as a psychosocial problem and successfully treated.

Physical examination on admission revealed a 4.8 $\mathrm{kg}$ infant with mild tachypnoea and a temperature of $37.5^{\circ} \mathrm{C}$. No other physical abnormalities were noticed. Chest $x$ ray film showed moderate bilateral hyperinflation. Arterial blood gases breathing room air showed $\mathrm{pH} 7 \cdot 39$, oxygen tension $7 \cdot 1 \mathrm{kPa}(53 \mathrm{~mm}$ $\mathrm{Hg})$, and carbon dioxide tension $4.5 \mathrm{kPa}(34 \mathrm{~mm}$ $\mathrm{Hg}$ ).

In the first two months of admission to hospital the main problems were failure to thrive, anorexia, and mild tachypnoea. Cystic fibrosis, immunodeficiency, malabsorption, and renal and metabolic abnormalities were excluded and it was (erroneously) thought that his problem was similar to that of his older brother. In the third month after admission the patient became more tachypnoeic and a repeated arterial blood gas analysis in room air showed oxygen tension $5 \cdot 1 \mathrm{kPa}$ and carbon dioxide tension $5.5 \mathrm{kPa}$. When given oxygen his oxygen tension rose to $39.3 \mathrm{kPa}$, suggesting ventilationperfusion imbalance.

Pulmonary function tests were performed using the infant whole body plethysmograph. ${ }^{4}$ Thoracic gas volume and specific airway conductance were normal $(150 \mathrm{ml}$ and $4 \cdot 1 \mathrm{sec} / \mathrm{kPa})$, whereas specific dynamic compliance was $0.296 \mathrm{kPa}$ (normal $=0.60$ $\mathrm{kPa})$. Measurement of forced expiratory flow revealed normal flow at resting lung volume (280 $\mathrm{ml} / \mathrm{sec}$ ). At 7 months an open lung biopsy examination was performed. Histological findings were mild thickening of the alveolar septa, and groups of desquamated type II pneumocytes and macrophages within the alveolar spaces, which were identified on electron microscopy studies. The picture was typical of desquamative interstitial pneumonia. Stains and cultures of the biopsy specimen for pneumocystis, bacteria, fungi, and acid fast organisms yielded negative results.

The patient was treated with chloroquine 10 $\mathrm{mg} / \mathrm{kg}$ in two divided doses. After one month of treatment he started to improve and his respiratory symptoms subsided, and after two months of treatment no supplemental oxygen was needed. Arterial oxygen tension in room air rose to $8.9 \mathrm{kPa}$ and he started to gain weight. After six months of treatment chloroquine was stopped for three weeks, at the end of which his arterial oxygen tension had fallen to $5 \cdot 7$ $\mathrm{kPa}$. Chloroquine was restarted and his oxygen tension rose again (Figure). After 16 months of treatment his weight reached the 3rd centile and after another year the 25th centile. Repeated arterial blood gas examinations yielded normal results. Ophthalmologic examinations were performed every six months and yielded complete 


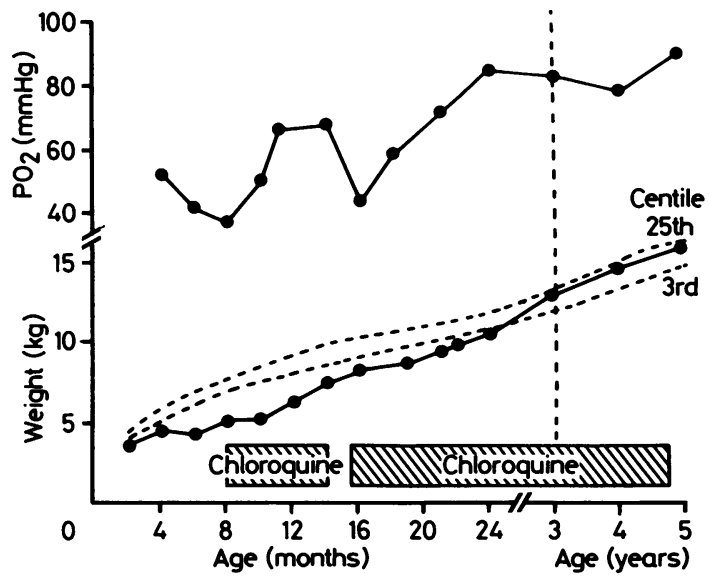

Figure Weight and arterial oxygen tension $\left(\mathrm{PO}_{2}\right)$ before and during treatment with chloroquine.

results. At the age of 4.5 years chloroquine was stopped. Six months later arterial oxygen tension was $12 \mathrm{kPa}$ and chest $x$ ray film and a xenon perfusion lung scan yielded normal results.

\section{Discussion}

Although spontaneous resolution of desquamative interstitial pneumonia may occur occasionally, ${ }^{2}$ there is little doubt that our patient responded to chloroquine, as stopping of the treatment resulted in deterioration of his condition and restarting the treatment brought about a second improvement. This response is similar to that originally noted by Tooley. ${ }^{3}$ Leahy et al reported an infant who was unresponsive to chloroquine alone but who responded to a combination of chloroquine and steroids initially and to chloroquine alone later. ${ }^{6}$

Although hyperinflation was evident on the chest radiograph, lung function revealed a normal thoracic gas volume more in keeping with the physiological pattern seen in adults.
Antimalarial compounds have been shown to inhibit in vitro antigen antibody complex formation and to split immune complexes. Raised concentrations of circulating immune complexes and deposition of immunoglobulin and complement in the lungs have been shown in patients suffering from idiopathic interstitial pneumonia. These findings suggest that antimalarial agents may be effective in the treatment of desquamative interstitial pneumonia through an immunosupressive mechanism.

Chloroquine is not an entirely harmless drug. The most serious complication is retinopathy, which is probably a dose related phenomenon. The alternative to chloroquine is treatment with steroids or cytotoxics, or both, which, apart from the variable response, also have side effects.

We suggest that chloroquine should be considered as an effective alternative treatment in desquamative interstitial pneumonia. Careful observation is needed to evaluate its efficacy and safety in children.

\section{References}

1 Barnes SE, Godfrey S, Millward-Sadler GH, Roberton NRC. Desquamative fibrosing alveolitis unresponsive to steroids and cytotoxic therapy. Arch Dis Child 1975;50:324-7.

2 Carrington CB, Gaensler EA, Coutu RE, Fitzgerald MX, Gupta RG. Natural history and treated course of usual and desquamative interstitial pneumonia. $N$ Engl $J$ Med 1978;298:801-9.

${ }^{3}$ Barnett HL, ed. Pediatrics. 15th ed. New York: AppletonCentury-Crofts, 1972:1315-6.

${ }^{4}$ Stocks J, Levy NM, Godfrey S. A new apparatus for the accurate measurement of airways resistance in infancy. $J$ Appl Physiol 1977;43:155-9.

5 Taussig LM, Landau LI, Godfrey S, Arad I. Determinations of forced expiratory flows in newborn infants. J Appl Physiol 1982;53:1220-7.

${ }^{6}$ Leahy F, Pasterkamp H, Tal A. Desquamative interstitial pneumonia responsive to chloroquine. Clin Pediatr 1985; 24:230-2.

Correspondence to Dr C Springer, Department of Pediatrics, Hadassah University Hospital, Mount Scopus, P O B 24035, Jerusalem 91240, Israel.

Received 21 July 1986 